Britt, B. A., and Kalow, W. (1970). Canadian Anaesthetists' Society fournal, $17,293$.

Daniels, J. C., Polayes, I. M., Villar, R., and Heare, F. W. (1969). Current Researches in Anesthesia and Analgesia, 48, 877.

Denborough, M. A., King, J. O., Ebeling, P., and Zaff, P. (1970). Lancet, 1,1138 .

Feinstein, M. (1963). Fournal of General Physiology, 47, 151

Harrison, G. G., et al. (1968). British Medical fournal, 3, 594

Harrison, G. G., et al. (1969). British fournal of Anaesthesia, 41, 844.

Harrison, G. G., et al. (1970). In Proceedings of the 3 rd Asian and Australasian Congress of Anaesthesiology, ed. L. Shea and B. Dwyer, p. 158. Sydney, Butterworths.
Isaacs, H., and Barlow, M. R. (1970). British Medical Fournal, 1, 275. Johnson, P. N., and Inesi, G. (1969). Fournal of Pharmacology and Experimental Therapeutics, 169, 308.

. Writt, B. A., Terreau, M. E., and Haist, C. (1970). Lancet, 2, 895.

Satnick, J. H. (1969). Anesthesiology, 30, 472.

Strobel, G. E. (1971) Lancet, 1, 40.

Sybesma, W., and Eikelenboom, G. (1969). Netherlands fournal of Vetinerary Science, 2, 155.

Weber, A. (1968). Fournal of Generql Physiology, 52, 760.

Weber, A., and Herz, R. (1968). Fournal of General Physiology, 52, 750.

Wilson, R. D., Dent, T. E., Traber, D. L., McCoy, N. R., and Allen, C. R. (1967). Fournal of the American Medical Association, 202, 183.

\title{
Long-term Ventricular Pacing in Treatment of Sinoatrial Block
}

\author{
T. J. BAYLEY
}

British Medical fournal, 1971, 3, 456-458

\section{Summary}

Six patients with symptoms due to sinoatrial block are described in whom no relief or improvement in block occurred when they were treated with isoprenaline or ephedrine. All six patients were treated by ventricular cardiac pacing with complete relief of symptoms. Despite the theoretical disadvantages of parasystole and loss of accrochage in treating these patients by ventricular pacing they have survived for periods of 18 months to over five years.

\section{Introduction}

Sinoatrial block occurs less often than atrioventricular block, and though it may be of no clinical importance some patients may have disabling symptoms (Shaw and Erant, 1970). If prolonged atrial standstill occurs without the appearance of an atrioventricular nodal or other pacemaker dizziness and even syncope may occur because of ventricular standstill. In some patients symptoms may occur because of ventricular bradycardia causing angina and low output syndrome. Treatment with atropine, ephedrine, and isoprenaline may be effective in controlling symptoms in some patients. When drug therapy is ineffective cardiac pacemaking may prevent recurrent syncope and other symptoms. All the cases reported here had disabling symptoms due to sinoatrial block which were not abolished by drug therapy but were relieved by ventricular pacing.

\section{Case 1}

A woman aged 70 when first seen in January 1966 complained of frequent momentary attacks, of 14 months' duration, in which she felt faint and during which she was observed to breathe deeply and to fidget with her clothes. The attacks had lasted a few seconds only, and though she had not lost consciousness she had had as many as 100 of these momentary "turns" a day. She had had good health in the past, and otherwise had no symptoms.

On examination there were no signs of heart failure, the blood pressure was $160 / 80$, and the pulse varied from extreme brady-

Queen Elizabeth Hospital, Birmingham B15 2TH

T. J. BAYLEY, M.B., M.R.C.P., Senior Medical Registrar cardia to rapid irregular tachycardia. There were no cardiac murmurs and the rest of the physical examination was normal Chest $x$-ray examination showed slight left ventricular preponderance. E.C.G. (Fig. 1) showed extreme sinus bradycardia with multifocal extrasystoles, both supraventricular and ventricular, with occasional paroxysms of rapid atrial fibrillation. At times the E.C.G. showed varying sinoatrial block varying from $1: 1$ to $3: 1$ in degree. The frequency of attacks was not altered by treatment with isoprenaline $30 \mathrm{mg}$ eight-hourly, and after a short period of temporary transvenous pacing a permanent inductively coupled coiled pacemaker with a transvenous electrode situated in the apex of the right ventricle was inserted. Further attacks did not occur during the remainder of her stay in hospital and she has remained free from symptoms in the four years since operation.

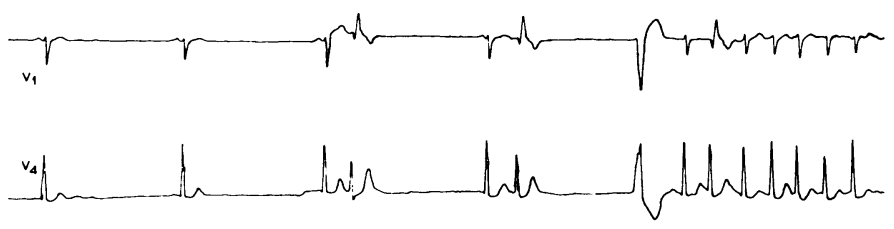

FIG. 1-E.C.G. in Case 1. Leads V1 and V4.

\section{Case 2}

A man aged 55 when first seen in August 1967 had been treated for hypertension since 1958 with reserpine and diuretics. Two weeks before admission he had had an attack of unconsciousness lasting for a few seconds and was admitted to another hospital. While there he had a further attack of unconsciousness and several episodes of dizziness. In addition, he had several short episodes of angina decubitus and breathlessness.

On admission to this hospital there were no signs of heart failure, B.P. was $150 / 110$, and the pulse varied from 30 to $52 / \mathrm{min}$. The rest of the physical examination was normal, apart from the fundi, which showed grade II hypertensive retinopathy. E.C.G. showed varying sinoatrial block from $1: 1$ to $3: 1$ with occasional nodal escape beats. Chest $x$-ray examination showed some left ventricular preponderance. A therapeutic trial with isoprenaline caused no improvement in the E.C.G. but his symptoms were relieved by temporary transvenous cardiac pacing. Permanent endocardial cardiac pacing was established on 11 August 1967. He has remained well and symptom free since that time, apart from an episode of left lower lobe pneumonia in April 1968.

\section{Case 3}

A man aged 66 when first seen in March 1966 had suffered from epileptiform attacks for six years. These were thought to be posttraumatic epilepsy in view of a head injury sustained eight 
years previously when he had a depressed fracture of skull. When seen in the outpatient clinic he had an epileptiform seizure during which he was noted to be pulseless. He was admitted to hospital and the E.C.G. was monitored continuously. During the first 24 hours in the ward he had several of these attacks, on each occasion total cardiac standstill was observed. E.C.G. showed varying sinoatrial block from $1: 1$ to $3: 1$, with episodes of total cardiac standstill and occasional multifocal ventricular extrasystoles. Temporary transvenous cardiac pacing relieved his symptoms and a permanent endocardial inductively coupled coil pacemaker was inserted on 11 March. It was thought that some of his attacks might be true epilepsy since the E.C.G. showed fairly numerous seizure-significant features occupying mainly frontotemporal sites in either hemisphere. He has been treated with phənobarbitone and phenytoin ever since. Pacemaking was satisfactory, and he was free from symptoms until April 1968 when his symptoms recurred. E.C.G. again showed varying sinoatrial block with periods of total cardiac standstill. Pacemaker failure was due to displacement of the endocardial electrode. The electrode was repositioned, the secondary (internal) coil replaced, and he has remained free from symptoms since that time.

\section{Case 4}

A man aged 54 when first seen in March 1969 had been given medical discharge from the Army in 1958. At that time he was found to have atrial fibrillation for which he was given digoxin. He had remained well, leading an active life, though taking $0.75 \mathrm{mg}$ of digoxin daily, until admitted on 9 March 1969 having had two episodes of loss of consciousness in the three days before admission with several fleeting epicodes of transient faintness.

On examination the pulse was slow, $36 / \mathrm{min}$, and irregular. There were long periods (4-5 seconds) of asystole alternating with rapid irregular rhythm of short duration. B.P. was $130 / 80$. Two days after admission, and despite treatment with isoprenaline, he had a further attack of loss of consciousness. E.C.G. (Fig. 2) showed periods of 4-5 seconds of total cardiac asystole, periods of sinus bradycardia, slow nodal escape rhythm, and short 2-3 second paroxysms of atrial fibrillation. Temporary transvenous cardiac pacing produced relief of symptoms, and a permanent inductively



FIG. 2-E.C.G. in Case 4. Lead II

coupled coil pacemaker was inserted on 28 March. He remained free from symptoms until June 1969 when he had a further episode of unconsciousness. This episode seemed to be due to pacemaker failure resulting from an increase in ventricular stimulation threshold. Satisfactory pacing was re-established with a highpower pulse generator. He was readmitted in October 1970 with symptoms of left ventricular failure due to paroxysms of ventricular tachycardia which were suppressed with procainamide $500 \mathrm{mg}$ four times a day. The paroxysms of ventricular tachycardia did not seem to be induced by parasystolic pacemaker stimulation, but it was decided to convert the pacemaker system to an "on demand" pacemaker (Devices). The E.C.G. showed sinoatrial and atrioventricular block. He remained free from symptoms.

\section{Case 5}

A woman aged 60 when first seen September 1969 had had her first episode of syncope in September 1968 while on holiday and was admitted to hospital where bradycardia was noted. She was treated with isoprenaline and was discharged after one week. Despite continuing treatment with isoprenaline she had further episodes of syncope and noted diminishing exercise tolerance until she was admitted to this hospital in September 1969.

On examination there were no signs of heart failure, B.P. was $130 / 80$, pulse varying from bradycardia, $30 / \mathrm{min}$, to regular tachycardia, 105/min. E.C.G. showed varying sinoatrial block with episodes of total cardiac standstill lasting for 5-6 seconds. Episodes of supraventricular tachycardia with $2: 1$ atrioventricular block were observed. She was symptomatically improved with temporary transvenous cardiac pacing, though episodes of tachycardia did occur which could be suppressed by fast stimulation frequencies. A permanent endocardial inductively coupled cardiac pacemaker was implanted on 8 September. She was free from symptoms until June 1970, when she was readmitted having had frequent paroxysms of tachycardia, and for this reason an epicardial "on demand" pacemaker was implanted. It was necessary to reposition the epicardial electrode one month later because of increased impedance probably resulting from fibrosis around the site of implantation in the left ventricle. She was readmitted in January 1971 because of sepsis around the site of implantation of the pacemaker; this was repositioned. She had had no further symptoms and paroxysms of tachycardia had been suppressed by digoxin.

\section{Case 6}

A woman aged 61 when first seen in August 1969 had had symptoms for about two months before admission. Her symptoms had been those of breathlessness on exertion, tiredne s, chest pain related to exertion, and frequent episodes of transitory dizziness. Her symptoms were not improved by treatment with both ephedrine and isoprenaline, and there was no increase in ventricular rate.

On examination there were no signs of heart failure, B.P. was $150 / 80$, and the pulse varied from 32 to $50 / \mathrm{min}$. E.C.G. showed varying sinoatrial block with occasional nodal escape beats. The heart was normal in size on chest $x$-ray examination and all other inve tigations were normal. She was free from symptoms when transvenous temporary pacing was used. A permanent endocardial inductively coupled coil pacemaker was implanted on 11 August 1969. She has remained free from symptoms since tha: time, though sinoatrial block persisted when the pulse generator was switched off.

\section{Discussion}

The frequency and disabling nature of the symptoms due to sinus bradycardia, the "lazy sinus," and sinoatrial block have been emphasized by Shaw and Erant (1970). They reported 41 cases with symptoms of recurrent syncope and angina, and noted the occurrence of paroxysmal atrial fibrillation and flutter in nine of them.

Atrial pacing for sinus bradycardia has been reported by Kastor, De Sanctis, Leinbach, Harthorne, and Wolfson (1969). These authors employed a specially angulated endocardial electrode which was inserted transvenously and positioned with its tip touching the wall of the right atrium near to the insertion of the superior vena cava. Satisfactory control of symptoms was achieved by this means in three patients. The difficulty of obtaining a stable position of the transvenous catheter in the atrium is, however, a serious problem with this method of cardiac pacing, and the method is unsuitable if there is coexisting atrioventricular block.

Left atrial pacing from a catheter electrode sited in the proximal part of the coronary vein has been reported for the treatment of sinus bradycardia in three patients by Moss, Rivers, and Cooper (1969). One died from unrelated causes, and in the other two there had been 31 months of uninterrupted pacing with relief of symptoms at the time of publication. Though complications did not occur the possibility of thrombosis of the coronary vein or perforation mean that this method has considerable risk.

Epicardial atrial pacing in two patients with sinus bradycardia has been reported by Clarke, Evans, and Milstein (1970). These authors employed an inductively coupled coil cardiac pacemaker with an external pulse generator (Abrams, Hudson, and Lightwood, 1960). As with all other methods for long-term atrial pacing this system retains the advantage of atrial transport, the P-R interval being little more than 0.2 second, and has the added advantage that reoperation for the replacement of batteries is not necessary. If atrioventricular block is also present this method will be unsuitable, likewise this will not control supraventricular arrhythmias 
which may occur in association with sinoatrial block (Short, 1954; Sandoe and Flensted-Jensen, 1969).

The six cases reported here had sinoatrial block with recurrent attacks of dizziness and faintness in all and syncope in three. In three cases sinoatrial block was complicated by paroxysmal supraventricular tachycardia (atrial fibrillation in two, flutter in one). Ventricular pacing was used in all patients, initially with the inductively coupled coil pacemaker, but latterly with a totally implanted demand pacemaker in two. Conversion was made in the latter because of frequent paroxysmal atrial tachyarrhythmias. Relief of symptoms was achieved in all patients, the longest interval with freedom from symptoms being more than five years.

Two criticisms may be made of ventricular pacing for the treatment of sinoatrial block. Firstly, the occurrence of parasystole with the risk of provoking ventricular tachydysrhythmias is a theoretical problem which in practice has proved to be of small significance. The occurrence of sudden death in patients with sinus rhythm with a fixed rate implanted pacemaker was reported by Sowton (1965). Most of these deaths occurred within the early postoperative period and were due to ventricular fibrillation. The risk of such a complication seems to depend on the energy of the stimulating pulse. The energy of the bimodal output of the pulse generator in the inductively coupled coil pacemaker system is probably well below the threshold for provoking ventricular tachydysrhythmias. The haemodynamic effects of parasystole are not disadvantageous (Sowton, 1965).

The second criticism of ventricular pacing for sinoatrial block is that of loss of atrial transport function which is preserved if atrial pacing is used. Sowton (1965) observed that when true synchronization of atrial and ventricular contraction, accrochage, does not occur the cardiac output, as judged by femoral atrial systolic and pulse pressures, is reduced by $25^{\circ}{ }_{0}$. Atrial pacing for sinoatrial block will achieve accrochage, though in the presence of varying sinoatrial block, as seen in some of the cases reported here when block varied from $1: 1$ to complete sinus arrest, competition will occur between sinoatrial node and the electrical pacemaker. Accrochage does occur, if intermittently, in these patients treated with a ventricular pacemaker, and none have shown any sign or symptom of low output failure since pacing was established.

Ventricular pacing does not prevent the occurrence of supraventricular tachydysrhythmias in these patients, but with a variable frequency pulse generator the dysrhythmia may sometimes be suppressed by using a rapid stimulation frequency. It has been possible to suppress tachycardia in this way in two of these cases.

The ideal form of treatment for such patients with sinoatrial block and recurrent episodes of cardiac standstill would be an atrial demand pacemaker. Despite the theoretical objections of parasystole, pacemaker-induced ventricular fibrillation, and loss of accrochage ventricular pacemaking has proved effective in relieving symptoms due to sinoatrial block in the six cases reported here.

I wish to thank Dr. A. Brian Taylor for permission to publish details of patients admitted under his care, and Mr. L. D. Abrams and Mr. D. B. Clarke, who operated on the patients.

\section{References}

Abrams, L. D., Hudson, W. A., and Lightwood, R. (1960). Lancet, 1, 1372. Clarke, M., Evans, D. W., and Milstein, B. B. (1970). British Heart fournal, $32,458$.

Kastor, J. A., De Sanctis, R. W., Leinbach, R. C., Harthorne, J. W., and Wolfson, I. N., (1969). Circulation, 40, 535.

Moss, A. J., Rivers, R. J., and Cooper, M. (1969). Fournal of the American Medical Association, 209, 543.

Sandoe, E., and Flensted-Jensen, E. (1969). Acta Medica Scandinavica, 186,111 .

Shaw, D. B., and Erant, J. (1970). British Heart fournal, 32, 557.

Short, D. S. (1954). British Heart fournal, 16, 208.

Sowton, E. G. (1965). British Heart fournal, 27, 311.

\title{
Prevention of Delayed Traumatic Facial Palsy
}

\author{
M. BRIGGS, J. M. POTTER
}

British Medical fournal, 1971, 3, 458-459

\section{Summary}

A previous impression that corticotrophin provided prophylaxis against delayed traumatic facial palsy has now been confirmed by the results obtained from the first 50 patients so treated.

\section{Introduction}

In a previous communication (Briggs and Potter, 1967) we outlined a scheme of treatment designed to reduce the incidence of delayed traumatic facial palsy and analysed the results of the

\footnotetext{
Department of Neurological Surgery and the Accident Service, Radcliffe Infirmary, Oxford OX2 6HE

M. BRIGGS, F.R.C.S., Postgraduate Research Fellow

J. M. POTTER, D.M., F.R.C.S., Consultant Neurosurgeon
}

first 16 patients so treated. There are now 50 patients who have been given a prophylactic course of corticotrophin gel (cf. Taverner et al., 1966) and the results confirm the protective value of this treatment.

\section{Patients and Methods}

The criteria used for the selection of injured patients who might benefit from prophylactic treatment have been the same as those employed for the earlier 16 patients: all patients who had a bleeding ear and who were shown also to have radiological evidence of a petrous temporal fracture on the same side. We had previously shown, by a retrospective survey of 70 patients with this combination of signs, that $27(38.5 \%)$ developed some degree of delayed facial weakness.

An eight-day course of corticotrophin gel was given, the first dose being administered on the day of injury. The dosage used was as follows: 80 units daily for three days, 60 units on the fourth day, 40 units on the fifth day, 20 units on the sixth day, and 10 units on both the seventh and eighth days. For children this dosage was reduced according to weight: about $1 \cdot 1$ units of corticotrophin being given per $\mathrm{kg} / \mathrm{body}$ weight. 